\title{
Analysis of Various Biblical Themes
}

\author{
Peter Bissonnet \\ Independent and Unaffiliated Researcher, Fusagasuga, Cundinamarca, Colombia \\ Email: peterkey1624@gmail.com
}

How to cite this paper: Bissonnet, P. (2018). Analysis of Various Biblical Themes. Open Journal of Philosophy, 8, 156-171. https://doi.org/10.4236/ojpp.2018.83012

Received: February 7, 2018

Accepted: May 6, 2018

Published: May 9, 2018

Copyright (C) 2018 by author and Scientific Research Publishing Inc. This work is licensed under the Creative Commons Attribution International License (CC BY 4.0).

http://creativecommons.org/licenses/by/4.0/

\begin{abstract}
The author believes that people are turning away from Christianity because (due to their free will) they cannot believe in the validity of various concepts, such as a unique and universal Crucifixion. They believe that everything was localized to this insignificant planet and nowhere else, and, hence, Christianity is pretty blasé and probably has a lot of deceptions, misconceptions, etc., just like most of human history has. Of course, the Crucifixion occurred locally on this planet, but the implications for other planets in far off galaxies are just as crucial. Do earthlings make better Christians than those in some galaxy residing out where the quasars roam? No, we don't. The Bible tells us to "prove all things"; in other words, reason analytically, responsibly, determine the truth! That is just what science does, or is supposed to do, but when scientists ally themselves too closely to government, their objectivity is capable of being bought or skewed by those governments, which keeps some subjects taboo as far as being investigated properly. This paper is trying desperately to determine what the truth is in those, admittedly strange events which have happened in the history of the New Testament. The author has also included a section on the search for new physical principles, by establishing working hypotheses and using these to analyze certain Bible miracles and such other phenomena which might seem appropriate. As a physicist and mathematician, the author finds the miracles of the Bible to be filled with a vast potential for discovery of new physical principles. The author hopes you will too.
\end{abstract}

\section{Keywords}

Unique and Universal Crucifixion, Synchronized Time Differentials/Intervals, Miracles, Search for New Physical Principles, Variable Gravitational "Constant", Weak Interaction, Representations of Prime Numbers and Prime Products

\section{Introduction}

Section 2 purports that the Crucifixion of Christ must be a single and universal 
Crucifixion throughout the entire universe and is therefore unique. This paper is in direct opposition to the changing views which question if there ever was a Crucifixion or, if there was, then whether or not Christ survived and possibly traveled to other parts of the world (Khan, 2009). This paper will defend the historical Christian position that the Crucifixion did happen because it can be cast into a single, universal, and therefore unique category. The following options (as determined solely by the author) will be examined.

1) The Crucifixion happened only on the earth and nowhere else, making the earth the "center of the universe" so to speak.

2) The Crucifixion happened at the same "instant" everywhere in the universe.

3) The Crucifixion happened/happens individually and separately at multiple times throughout the universe.

4) The Crucifixion happened/happens and is orchestrated by extra-terrestrials.

5) The Crucifixion happened/happens at synchronized time differentials/ intervals throughout the universe.

It is assumed that the Crucifixion will only occur in intelligent societies that are monotheistic. It is further assumed that these monotheistic societies have a history of barbarism, since the Crucifixion is a supreme act of barbarism itself.

Section 3 discusses type 1 and type 2 miracles with the emphasis being placed in this paper upon the analysis of type 2 .

\section{On a Proposed Synchronicity of Time Differentials/Intervals to Explain the Uniqueness of a Universal Crucifixion}

\section{Analysis of the Options}

Option 1: The Crucifixion happened only on the earth and nowhere else, making the earth the "center of the universe" so to speak.

Modern Astronomical Point of View: We know through astronomy that earth is nothing more than a planet in a solar system on the outer edge of a spiral galaxy which we call the Milky Way galaxy. We have a huge neighboring spiral galaxy called Andromeda a couple of million light years away that is headed towards us. We know that eventually we will collide with Andromeda and what our fate will be, as we have seen in pictures taken of other colliding galaxies, ending with huge black holes orbiting around each other and either "eating" or spinning off solar systems and planets into the cold vast blackness of space. This doesn't sound like the description of a planet which is unique enough to be the "center of the physical universe" (the Ptolemaic system), or of a spiritual center of the universe, in order to accommodate such a great spiritual occurrence as the birth, life, and crucifixion of Jesus Christ, the Son of God, who is the author and creator of the entire universe.

$15^{\text {th }}$ Century Point of View: The author is currently looking at a picture of the Madonna and San Giovannino (Lin, 2016; Lillie, 2014) and which was painted by Domenico Ghirlandaio and which depicts in the background a modern-day 
UFO with a man and a dog looking at it. The painter seems to be saying that there were two realities at that time. The first reality is the religious one he dealt with every day, and the one which he was taught and painted. The second reality was the one imposed upon him by the appearance of a strange craft in the sky, an apparently objective reality and not a hallucination, since the dog that was with him also acknowledged its presence.

The author thinks (and these are solely his ideas and were not copied from any other source) that the following ideas can be deduced from the painting itself. Why would Domenico Ghirlandaio have painted this UFO, unless, he expected the average person in Italy at that time to also recognize this duplicity of realities. If this were not true, then the average person at that time would have assumed Ghirlandaio was having hallucinations himself. It would also seem obvious that Domenico Ghirlandaio was dissatisfied with official and religious explanations of this phenomenon, which led him to insert this phenomenon unobtrusively into the background of one of his religious paintings. We scientists in the modern era must be indebted to him and others like him for having the moral courage to let the truth out, in spite of official views to the contrary.

Still, this seems to imply that there was at least one planet in our galaxy which had mastered interplanetary travel in the $15^{\text {th }}$ century, while earth was still a very mediocre and primitive backwater planet in terms of technology...hardly a beacon for the candidate of "center of the universe". The author has often wondered whether or not a planet's mastery of interplanetary/intragalactic travel implies that such planetary societies are closer to the truth and reality of God, since they can see clearer the laws and patterns of the universe, which we on earth cannot as yet see. If this be a true observation, then the UFO painted by Ghirlandaio would represent a planetary society which would have a greater claim than earth to be called the "center of the universe". At any rate, the author considers that there is no uniqueness or universality in this option, as far as the Crucifixion on earth is concerned.

Option 2: The Crucifixion happened at the same "instant" everywhere in the universe.

This implies that all monotheistic societies in the entire universe reached the same spiritual development in need of the Crucifixion at the same "instant" so to speak, regardless of locality, even though some societies were hundreds, thousands, or even millions of years ahead or behind other societies. This does not make sense, as some societies evolve slower or faster than others. Also, this would seem to contradict free-will, given to all these societies by God. Further, to have the Crucifixion occur at the same "instant" everywhere would assume that all of the monotheistic societies, wherever located in the universe, would be acting in unison towards God's plan for a universal Crucifixion. Again, this contradicts the concept of free-will, which might be considered the equivalent of spiritual entropy, which would act in disharmony against such a universal plan. In addition, monotheistic societies which had not yet developed on whatever planet would be missing out on the Christian message. The author believes that 
this option does not contribute to the concept of uniqueness.

Option 3: The Crucifixion happened/happens individually and separately at multiple times throughout the universe.

This option is easily relegated to the trash-bin because of the following arguments. First, there is no one unique Crucifixion, but many. Secondly, for there to be many individually and separate Crucifixions occurring at multiple times also implies that there are many individual and separate temptations of Christ by sa$\tan$ (no, the author will not dignify him by capitalizing his name). Satan may be supremely evil, but he is not stupid. If Christ turned him down once, then it would destroy the Christian message, if on some planets Christ accepted satan's offer and, on others, Christ rejected satan's offer, leading to internal inconsistencies within Christianity. Also, this option may imply that there are many different hells instead of a universal hell, since when Christ died, he descended into hell, not hells, according to the Apostle's Creed. There would have to be many hells for Christ to descend into, otherwise we are again faced with a sort of discontinuity; namely, that Christ descends into a universal hell many times following the many times that he is crucified. This makes no sense at all! There is no uniqueness in this option.

Option 4: The Crucifixion happened/happens, being orchestrated by extra-terrestrials.

In the extreme, this would imply that there is no God, and that the extra-terrestrials are merely using their advanced technology to pass themselves off as God or gods, which again defeats Christianity, as Christ is the Son of God. In the less extreme, this would imply that the extra-terrestrials are to be interpreted as angels. However, it says in the Bible that man was made a little lower than the angels (Psalms 8: 4-5) and that Christ himself in bodily form was made a little lower than the angels for the suffering of death (Hebrews 2:9). The current concept by the general public who have witnessed such extra-terrestrials, seems to be that extra-terrestrials are firstly, made of flesh, secondly, need spacecraft in order to travel, and, thirdly, some of the general public even claim that they have witnessed dead aliens. Thus, we have three characteristics that are not part of the angelic concept. There is no uniqueness in this option.

Option 5: The Crucifixion happened/happens at synchronized time differentials/intervals throughout the universe.

Consider the definition of coincidence: two or more events happening at the same place at the same time. Now consider the reverse of this definition: one event occurring at more than one time and at more than one location. The author believes that this reversal of coincidence is the simplest way to convey the concept of synchronicity of time differentials/intervals. This paper assumes that this can happen based upon two characteristics of God: 1) God is eternal (1 Timothy 1:17) and therefore lies outside of time, and 2) what is impossible for man is possible for God (Luke 18:27).

This option is based upon the assumption that 'time differentials/intervals' are 
different than time itself in the sense that there is such a thing as absolute time, which exists in short intervals and cannot be quantified or measured or put into the form of equations. For example, in order to show that absolute time exists, it is valid and meaningful to make the statement "At this moment, all life forms throughout the entire universe are in the process of performing some action." This is based upon the assumption that planetary systems at the far reaches of the universe do exist at this moment, that they have life forms, and that those life forms are in the process of performing some sort of action at this moment. We can ask this question, regardless of the distance between planetary systems and regardless of the value of the speed of light. This has nothing to do with attempting to communicate with these planetary systems or with relativity.

Further, this option is based upon the assumption that time differentials/intervals on world lines across the universe can be synchronized. Consider the following: suppose that God draws a straight line and this straight line represents one unique event; namely, the Crucifixion of Christ. Now consider that along this straight line, God aligns time differentials or small intervals of time from innumerable various civilizations which are monotheistic. Many of these time differentials occur hundreds, thousands, or even millions of years ahead/or behind other civilizations. This straight line represents only one unique Crucifixion of Christ. The Crucifixion of Christ occurred on earth two thousand years ago. On some other planet with a monotheistic civilization, it might have occurred hundreds of thousands of years ago. There are some civilizations in which the Crucifixion has not yet happened, because they have not yet evolved to that point in which the Crucifixion is necessary to their history. However, it is important to realize that, as a result of these synchronized time differentials/intervals, it is the same unique Crucifixion that has happened, is happening, or will happen.

How large is a differential? When you are dealing with a line on a sheet of paper in front of you, it is close to zero. How large is a differential or interval if you are dealing with the age of the universe? Perhaps it is the entire life-span of Christ which is about thirty-three years here on earth. This paper advocates that the Crucifixion of Christ on all of these various planets, past, present, and future, is not the same in the sense that on some planets, there may not be intelligent life which look like those from other planets, but vary in appearance due to DNA structure or damages to DNA structure as a result of radiation composition and intensity on the planet's surface and/or the impact of strong gravitational, strong electric, and strong magnetic fields from the planet itself or from outer space; the mineral composition of each planet from which organic or possibly inorganic life forms could evolve; availability of water or water substitutes; etc. In short, it is the Holy Spirit that conceives Christ on all of these planets, and that it is not the bodily form that is important, but it is the Spirit of God, the Holy Spirit, and the Spirit of Christ acting through the Crucifixion event that is the same on all these planets. The author believes that this option 5 provides the only viable solution for one and only one unique Crucifixion of Christ throughout the entire cosmos. 


\section{The Search for New Physical Principles}

\subsection{Overview}

The author is, in effect, attempting to offer tentative and plausible "explanations" to some of the Bible miracles and some other phenomena. Furthermore, for any Christian readership, the author claims that his "authority" (if that be the proper word or perhaps 'basis' should be used) for such "explanations" lies in two places in the Bible: 1) 1 Thessalonians 5:21 says "Prove all things..." This is an assertive or categorical proposition, which is totally consistent with science. Note that it does not say prove "some" things, it says prove "all" things, which, by the way, is an anathema to most governments of today. 2) in Matthew 17:20, Christ says "If ye have faith as a grain of mustard seed, ye shall say unto this mountain, remove hence to yonder place; and it shall remove; and nothing shall be impossible unto you." This is a conditional or hypothetical proposition because it is prefaced with the word "If". Christ is affirming our ability to do seemingly miraculous types of things; provided that we possess other qualities. $\mathrm{He}$ is definitely NOT saying that we will NEVER be able to do seemingly 'miraculous' things; he affirms that if we had these other characteristics or qualities, that nothing would be impossible for us.

The author believes that the serious reader of this paper must assume the obligation of reading the other papers of the author mentioned in the reference section. This is so, simply because of the vast scope of concepts which are utilized in the writing of this paper. It is simply impossible to recreate in detail all of the content and concepts of previous papers.

\subsection{Miracles}

What is a miracle? The author provides his own definitions.

It could have two basic connotations. 1) It could mean an event or series of events created by God directly, which do not seem to obey any established laws of causation. A simple example would be God talking to a prophet either directly or through an angel. Another example would be the descent of the Holy Spirit upon the Apostles in Jerusalem, and a fulfillment of a prophecy of Joel (Acts 2: 1-31), which, among other things, allowed people of different nationalities to understand what was being said in languages not their own. How would you ever explain, rationally, an act of divine intervention? 2) It could also mean an event or series of events which can only be understood at some evolved level of technological understanding by some evolved intelligent life forms, but it might take hundreds or possibly thousands of years of evolution to reach such a level of understanding, as in the case of advanced technology. A possible example of (2) would be the UFO. How does a spacecraft weighing hundreds of tons move about in an instant with practically zero inertia? Will we have to wait hundreds or will we have to wait thousands of years in order to answer that question?

Is there a theoretical scientific explanation for miracles of type (2) that we can address right now? Any so-called explanations would necessarily be theoretical, 
not factual, since we would be dealing presumably with an unknown type of future science. The reader should not take this to mean that this author considers Christ to be some type of extra-terrestrial, but that when God or Christ deal with the universe and the beings in it, they are at liberty to use miracles of the type (1) or those of type (2), i.e. advanced science which we are not yet aware of and which obey the laws of the universe which they have created.

\subsection{Working Hypotheses}

The working hypotheses of this section are that:

1) there is a variable gravitational scalar "constant" at work in the nucleons of all nuclei in conjunction with the weak interaction (Bissonnet, 2015).

2) there is an associated (and interpreted to be) new type of electromagnetic field which can be derived from this variable gravitational scalar "constant" (Bissonnet, 2015), which is presumed to permeate all living things and is presumed to be part of the biologically active force which is present (keeping in mind that God is the true source of all life), together with the soul in the phenomena called life, which involves the double helix of DNA. The actual formula for this new type of electromagnetic field is very complex, but for those of you who are mathematically inclined, please see reference 2 for the actual derivation.

3 ) the mind (both conscious and subconscious), in conjunction with the soul, can manipulate this new type of electromagnetic field.

4) the cosmos is somehow created from and based upon prime numbers and prime products (Bissonnet, 2018). See reference 3 for the derivation of the double helix from a consideration of prime numbers, and the possibility that the universe is built mathematically upon prime numbers, simple prime products, and multiple prime products. The double helix of prime numbers merely represents one of the facets or representations of prime numbers, simple prime products, and multiple prime products and could be responsible for life, while the hyperbolic representation could be intimately related to the origins of quantum mechanics and special relativity. The author believes that each representation (Bissonnet, 2018) of prime numbers, simple prime products, and multiple prime products is responsible for some particular creation in/or foundation of the cosmos. No, the author is not suggesting that God is, himself, some sort of mathematical creation, but only that these representations could be a tool by which God manipulates His creations within the universe. The author discusses four representations he has discovered in reference 3. He has not as yet found how the other two, the parabolic and the triangular, can possibly be utilized.

\subsection{Analysis of Miracles of Type 2}

\subsubsection{Consider Christ Walking on the Water (Collins, 2011)}

Suppose an asteroid (Bissonnet, 2015; Bissonnet, 2017a), located quite a distance from the earth, yet still within the gravitational attraction of the earth, entered a small region of space which was governed (for some unknown reason or other; the cause of such an anomaly is not important for our purposes) by a different 
gravitational "constant" $G$ ( $G$ might be considered to be a complex variable dependent on space and time, in which case $G$ would be understood to be $|G|$ ). The gravitational force on the asteroid would then be $F=\frac{|G| M_{\text {earth }} m_{\text {asteroid }}}{R^{2}}$ where $R$ is the distance from the center of the earth. This can be recast into the standard form such as follows $F=\left(\frac{G_{0} M_{\text {earth }}}{R^{2}}\right) m_{\text {apparent }}$ where $m_{\text {apparent }}=\left(\frac{|G|}{G_{o}}\right) m_{\text {asteroid }}$.

Thus, we see that the apparent inertial/gravitational mass of the asteroid has changed due to the factor $\left|G / G_{\mathrm{o}}\right|$. This type of inertial/gravitational mass is considered to be entirely separate from the type of inertial mass determined by the Higgs' field in particle theory. From this concept of what might be referred to as a "variable" inertial/gravitational mass, there are three types of strange phenomena which can be deduced.

Levitation is one of these strange phenomena, which obviously can be deduced very quickly, assuming that $|G|<G_{o}$. This might account for Christ being able to walk on the water.

There are two more even stranger consequences which can be deduced. Consider the following example.

Suppose there is a baseball traveling with a momentum vector $\mathrm{p}_{1}$, and it is headed for a large flat sided block of stone which is at rest. We insist upon flat sidedness so that the recoil will be simple and predictable. We assume that the conservation of momentum holds before and after collision, namely:

$p_{1}=p_{2}+M_{o} v$, where $M_{o}$ is the mass of the block of stone and $\mathbf{v}$ is its recoil velocity vector, and $\mathrm{p}_{2}$ is the recoil momentum of the baseball after collision. Now suppose we are able to "activate" the "variable" gravitational scalar "constant" within the nucleons of the stone block.

We now have $\mathbf{p}_{1}=\mathbf{p}_{2}+\left|G / G_{0}\right| M_{0} \mathbf{v}$. If we let $|G| \rightarrow 0$, we then have $\mathbf{p}_{1}=\mathbf{p}_{2}$ so that the baseball does not bounce off the stone block! Now consider if the baseball were a photon, then there would be no reflection, hence invisibility!

Now consider the associated idea of transposition of matter or in other words, matter passing through matter with no impedance. If we go back to the baseball, we have $\mathbf{p}_{1}=\mathbf{p}_{2}$, but the stone block is still there under the condition of $|G|=0$; however, it has no inertia by the very fact that $|G|=0$. We therefore have to conclude that the baseball traverses the stone block with no impedance to its passage! These are the very strange theoretical consequences deduced from the idea of zero inertia and a variable gravitational "constant".

\subsubsection{Christ Feeds the Five Thousand (Bissonnet, 2017b)}

Jesus Feeds 5000 People (Matthew 14:13-21; Mark 6:30-44; Luke 9:10-17; John 6:1-15)

Matthew 14 
19 And he commanded the multitude to sit down on the grass, and took the five loaves, and the two fishes, and looking up to heaven, he blessed, and brake, and gave the loaves to his disciples, and the disciples to the multitude.

20 And they did all eat, and were filled: and they took up of the fragments that remained twelve baskets full.

21 And they that had eaten were about five thousand men, beside women and children.

These three verses are taken from URL https://www.kingjamesbibleonline.org/Matthew-Chapter-14/

In 3.4.1, the author dealt briefly with the so called gravitational "constant" in the range,

$0 \leq G \leq G_{o}$ where $G$ represents a variable gravitational "constant", and $G_{o}$ represents the usual Newtonian gravitational "constant" value. The scale dealt with was the sub-nuclear level regarding the weak interaction: hardly a range at which gravity can be measured, yet a close approximation to the Fermi constant was derived (Bissonnet, 2015) based upon a variable $G$ in the so-called weak interaction. It is, however, the belief of the author that the universe operates quite differently in the range $0 \leq G \leq G_{o}$ as opposed to the range $G \geq G_{o}$.

Now let us look briefly in our macroscopic level at the range $G \geq G_{o}$, wherein the anomaly lies, in that there appears to be two solutions to the same problem in this thought experiment. Consider that you have some object, such as a loaf of bread. Assume further that you have a button on some kind of imaginary control panel before you, which you can push to increase the value of the gravitational "constant" around the loaf of bread. If you push the button so that the gravitational "constant" doubles, then you would expect that the loaf of bread doubles its weight. This is one solution. The button is required to be infallible, so that the requirement of doubling the weight is incontrovertible

$W_{o}=m_{o} g_{o}$ represents the beginning weight of the loaf of bread, and $g_{o}$, we know, is proportional to $G_{o}$. If we double $G_{o}$, then we must also double $g_{o}$. Hence the final weight of the loaf of bread is $W=2 W_{o}=m_{o} g=m_{o}\left(2 g_{o}\right)$.

However, also consider that the possibility exists that we live in a universe in which there is some sort of requirement for gravitational stability. In other words, consider that whenever the button is pushed to increase the value of the gravitational "constant", that the universe resists the increase and tries to maintain the normal stable value of the gravitational "constant" of $G_{o}$. Remember, however, that the button is required to be infallible, and that there must be a doubling of the weight. What then is the answer to this dilemma? Herein lies the anomaly. How is the requirement of gravitational stability to be achieved, while at the same time insisting on the requirement of the doubling of weight? The answer is quite simple and requires a simple re-interpretation. We again rewrite the final weight of the loaf of bread as

$$
W=2 W_{o}=m_{o} g=m g_{o}=\left(2 m_{o}\right) g_{o}
$$


In other words, we end up with two loaves of bread instead of one.

\subsubsection{The Miracle at the Wedding at Canna}

John 2:1-11 King James Version (KJV)

1) And the third day there was a marriage in Cana of Galilee; and the mother of Jesus was there:

2) And both Jesus was called, and his disciples, to the marriage.

3) And when they wanted wine, the mother of Jesus saith unto him, they have no wine.

4) Jesus saith unto her, Woman, what have I to do with thee? Mine hour is not yet come.

5) His mother saith unto the servants, whatsoever he saith unto you, do it.

6) And there were set there six water pots of stone, after the manner of the purifying of the Jews, containing two or three firkins apiece.

7 Jesus saith unto them, Fill the water pots with water. And they filled them up to the brim.

8) And he saith unto them, Draw out now, and bear unto the governor of the feast. And they bare it.

9) When the ruler of the feast had tasted the water that was made wine, and knew not whence it was: (but the servants which drew the water knew;) the governor of the feast called the bridegroom,

10) And saith unto him, every man at the beginning doth set forth good wine; and when men have well drunk, then that which is worse: but thou hast kept the good wine until now.

11) This beginning of miracles did Jesus in Cana of Galilee, and manifested forth his glory; and his disciples believed on him.

From URL: https://www.kingjamesbibleonline.org/John-Chapter-2/

This is a difficult one to explain, because there are literally three solutions to the problem!

Let us consider the first solution. We know that water consists of water molecules consisting further of hydrogen and oxygen atoms. We know that wine consists of basically alcohol and sugars consisting of hydrogen, carbon, and oxygen atoms arranged into specific molecules. Jesus could have gone to all of the problems of transmutation of matter-dissecting the nuclei of atoms and rearranging them into their proper place in molecules with the correct atomic orbital electrons, but why go to all this trouble! The second solution is to use 3.4.1 above by changing the gravitational "constant" of the water to zero, so that it becomes invisible and can pass through the side of the barrel or jar because of transposition of matter discussed above. The same procedure could be used upon wine at some other location. The water goes out and the wine comes into the water pots or jars, and no one at the wedding could tell the difference. The third solution is duplication of matter discussed in 3.4.2 above. What if there was a small amount of wine at the wedding, but not enough to serve everyone. It would have been a simple procedure to use duplication of matter to increase the 
amount of wine and then use the procedure of the previous second solution-the water out of the water pots and the wine into the water pots.

\subsubsection{Auras and the Imprinting of Aural Effects}

Many Holy figures are represented with halos of light surrounding their heads and/or bodies. The postulated new type of electromagnetic field (Bissonnet, 2015) might contribute to this effect as well as the Kirlian aura (Carroll, 1994; Krippner \& Rubin, 1974). The Shroud of Turin could also be the result of a type of electromagnetic "photography" by possibly this new type of electromagnetic field. The Scriptures say that Jesus gave up the ghost while still on the Cross (Matthew 27:50), but what if this new type of electromagnetic field was a residual field that was still left in the body of Christ and actually imprinted his features after he was covered with the burial cloth and placed into the stone crypt?

The careful reader may object saying that as a result of 1 John 1:5, which essentially says that God is Light, that this paper is trying to derive God himself by invoking this new type of electromagnetic field. The author certainly thinks that this is a valued objection. The only way out is to assume that there are several types of light. One type is the Maxwellian electromagnetic field which we know is the same type of light emanating from the Sun, as well as the type that shows up on your monthly electric bill. The second type of light is the presumed electromagnetic field (but not Maxwellian) derived in reference 2 and may be the type of light connected with the power source of UFO's, spontaneous human combustion, and the soul (not the same as the spirit). There is even some extremely non-scientific anecdotal "evidence", given by the now deceased journalist and UFO writer, John A. Keel, that UFO reports and reports of poltergeist cases (taken from the years 1842-1886) (Keel, 1970) increased and decreased in unison, which, if true, might indicate a common cause regarding type of power source, and that poltergeist cases might be related to this second type of electromagnetic field. The third type of light, the author believes, is connected with God, Jesus, and the Holy Spirit, as already mentioned, in "God is Light".

The concept of the aura is best shown in the Transfiguration of Jesus (Matthew 17:2). This would be a manifestation of the third type of light mentioned above. In the opinion of the author, the aura is also suggested by the following in Ephesians 5:14 "Wherefore he saith, awake thou that sleepest, and arise from the dead, and Christ shall give thee light." To the author, this means that Christ will put the soul (together with its associated second electromagnetic field) in addition to the Light of God, back inside the deceased body, thus bringing it back to life.

\subsubsection{Spontaneous Human Combustion (Bord, 1989)}

See Ref. 4, p. 63 for cases. Such cases are documented by police and fire departments. Even Charles Dickens incorporated such an incident into his novel Bleak House (Watson, 2005). Spontaneous human combustion (Watson, 2005) basically is the usually incomplete cremation or conversion of a majority of the human body to ash in the absence of the high temperatures normally necessary for 
commercial cremation, and, at the same time, with a seemingly minimal effect on the nearby environment of the unfortunate person to whom this is happening. This might fall under our working hypotheses, in the sense that the new type of electromagnetic field is hypothesized to have its source in the individual nucleons of the human body, which are innumerable. This new type of electromagnetic field, under our working hypotheses, is allied with the mind and soul and can possibly separate from the human body upon the death of the body, in which case we would now have an apparitional form and a dead corpse, but the corpse is intact and has not turned to ash. Perhaps there is a set of extremely rare circumstances in which this new type of electromagnetic field is forced to prematurely vacate these countless nucleons, which comprise all of the bones, skull, ligaments, tendons, muscles, and various tissues constituting the human body, giving rise to an intense source of heat powered directly from the weak interaction of each nucleon and reducing to ash every cell in the body to which it comes into contact.

\subsubsection{Telekinesis/Psychokinesis or Tractor Beam}

In Matthew 17:20, Christ says "If ye have faith as a grain of mustard seed, ye shall say unto this mountain, remove hence to yonder place; and it shall remove; and nothing shall be impossible unto you."

This statement sounds very much like the conscious mind manipulating telekinetic/psychokinetic powers on a large scale or even like a tractor beam from Star Trek. If it is in the nature of a tractor beam, then the aforementioned new electromagnetic field based upon a gradient in the gravitational "constant", seems like an ideal candidate for "reaching out" and moving or grabbing something.

\subsubsection{Poltergeist Effects (Williams and Ventola, 2011)}

Previously mentioned in section 3.4.4. Similar to Telekinesis or Psychokinesis, but instead, this paper assumes poltergeist effects to be produced by the subconscious mind and therefore falls under our working hypotheses of a variable gravitational scalar "constant". Poltergeist effects also include the movement of objects and the affecting of electrical currents of the Maxwellian type. The postulated new type of electromagnetic field would make a good candidate for explaining these types of effects. Reference 14 presents that poltergeist activity falls off with the same type of mathematical formula as the Yukawa potential $\frac{1}{r} \mathrm{e}^{-a r}$. It is known that the Yukawa potential is a solution of the Klein-Gordon equation.

\subsubsection{Life Itself}

Life itself seems like a miracle. It is that peculiar something that distinguishes a moving bug from a block of granite. Consider that life is impossible without DNA on this planet and on all other planets. The double helix form of DNA can be derived mathematically (Bissonnet, 2018) using prime numbers. How to relate those prime numbers and the associated prime products which fall along the double helix to the real-life molecules which actually make up the DNA struc- 
ture is a problem. How to incorporate the second type of electromagnetic field based upon a variable gravitational "constant" as a contributor to the life-force, assumed to have its source with God, is another problem.

\section{Conclusion}

This conclusion section takes a no-holds barred approach to scientific discovery. When you are faced with an unknown phenomenon, take whatever steps you can (assuming that they are legal and moral) to solve it. Don't let scientific conventions or barriers stand in your way, otherwise you are not in control of your agenda. If authority figures tell you it can't be done, they usually have an agenda of their own or they have limited imagination. If you feel strongly about any problem, then take it home and work on it sub-rosa during your spare time. If something seems miraculous but you are not sure whether it is a type 1 or a type 2 miracle, then use common sense to try and determine your course of action. Remember, the goal is to achieve a new scientific principle!

This paper encompasses a large amount of information, and it is difficult to come up with a conclusion for each particular item mentioned. Regarding Section 2 on the subject matter of synchronicity, the author believes that it is a rational way to explain the universal uniqueness of the Crucifixion. One way that this synchronicity could be proven or disproven is to encounter advanced civilizations via UFO contact or some other method and ask them! However, it may be difficult to prove the fine difference between option 3 and option 5 by asking beings from another monotheistic society. The key difference between these two options is whether or not there was one temptation of Christ by satan (option 5) or whether there were many temptations of Christ by satan (option 3). The answer to this conundrum may not lie in the physical universe but in the spiritual realm, but how many times do we have the opportunity of asking God or Christ or the Holy Spirit or the Virgin Mary or angelic beings, etc. for information on questions such as this. We may never know but the use of logical and analytic deduction can often times lead us in the proper direction toward rational conclusions. The author has an unshakeable belief that option 5 is the correct answer to this conundrum.

Instead of individual conclusions for each item discussed in Section 3, the author has decided to give a generalized major purpose of this paper in order to show that even though Christianity has many difficult to explain phenomena from the universal and unique Crucifixion to the Shroud of Turin to levitation and duplication of matter, that the reader can be assured that we are at all times dealing with a good God and a rational God, who is THE master mathematician. The author believes that this good God even took the time to create a method of intragalactic space travel, based upon the weak interaction, so that the intelligent creatures that $\mathrm{He}$ created would not feel loneliness due to their seeming isolation in the tremendous immensity of space.

The author has been asked by the reviewer to include a direction for innovative research. The working hypotheses above, with the exception of number 4 , 
are based upon the variable gravitational "constant", which is assumed to have its basis in the so called weak interaction. The author, in reference 2, using the concept of a variable gravitational "constant", derived a very close approximation to the Fermi constant, which has its source in the weak interaction. Yet, there does not seem to be any experimental evidence of such a phenomenon. The one possible clue to this phenomenon may lie in a certain peculiarity of neutrinos. Remember that during the course of the weak interaction, a neutrino/anti-neutrino and a positron/electron is emitted. It seems that all neutrinos are so called left-handed neutrinos. There are no right-handed neutrinos! Peculiar, isn't it? We also live in a gravitationally stable universe with a gravitational constant which is unvarying. People and objects just don't suddenly fly up into the air because they happened to walk into a region where the gravitational 'constant' was in the process of changing. Could there be a correlation between these two ideas; namely, is the fact that we live in a universe with a constant of gravitation related to the fact that there are no right-handed neutrinos? In the alternative, is the life-time of a right-handed neutrino so incredibly small, regarding its participation in the weak interaction, that it just seems like it does not exist? Or can you take a left-handed neutrino, unroll it, so to speak, and roll it back up as a right-handed neutrino? Laughable? Quiensabe! Could the right-handed neutrino be a quantum of the variable gravitational 'constant' field? Fortunately, there does seem to be some light in the tunnel in this regard. The previous case for left-handed neutrinos is based upon the neutrino having zero mass; hence, there are no right handed-neutrinos in the so-called Standard Model (Webber, 2005). However, there does seem to be experimental evidence that neutrinos do have a finite mass so that both left-handed and right-handed neutrinos must exist and that right-handed neutrinos may interact in a much shorter time period than originally thought or they react much more feebly in the weak interaction so as to be undetectable. Thus, there could ultimately be a case made for a variable gravitational "constant" in the weak interaction, because it is not often that one can derive such an important constant as the Fermi constant using a variable gravitational "constant". There must be a connection! The accepted value of the Fermi constant in the 1960 's was $1.41 \times 10^{-49} \mathrm{ergcm}^{3}$. The accepted value today is $1.43 \times 10^{-49} \mathrm{ergcm}^{3}$ and the value calculated in reference 2 is $1.419 \times 10^{-49} \mathrm{ergcm}^{3}$.The very fact that such a close approximation was able to be made suggests strongly that right-handed neutrinos do exist and take part in the weak interaction! Whenever we have a number such as $A \times 10^{B}$ units, then it would have to be a very small probability indeed in order to obtain a very close approximation to the actual experimental value by looking at the intersection of the probabilities $\mathrm{P}(\mathrm{A}) \mathrm{P}(\mathrm{B}) \mathrm{P}$ (units) in which case $\mathrm{A}, \mathrm{B}$ and 'units' would all have to be very close to, or in the case of 'units', exactly at their correct values; all this just from making a deduction from an outlandish proposition that the weak interaction has an, as yet, undetectable phenomenon, namely, a variable gravitational "constant”! 
The author has also been asked by the reviewer to include the deficiencies of this article. One major deficiency is that the author has chosen to defend Christianity and to view Christian miracles as real events: unforgiveable heresies in the eyes of a majority of today's modern scientists, who view Christianity as a collection of anti-science tripe. Another deficiency is that the author has chosen to analyze miracles which he deems as type 2 , when in reality they could be type 1 and therefore unanalyzable. In analyzing the concepts of levitation, invisibility, and transposition of matter, the author made the assumption that the conservation of momentum applied to the analysis. What if it does not? The author made the assumption that the antisymmetric tensor he derived in reference 2 could be interpreted as a new type of electromagnetic field (non-Maxwellian). What if this interpretation is incorrect? Another deficiency is that the author is sure that there are more phenomena, not necessarily religious, which can be analyzed from the point of view of a variable gravitational "constant". Some of these deficiencies exist mainly in their omission from this paper; such subjects such as the following: Teleportation/Instant Transference, Multiple Personality Disorder, Apparitional Experience, Raising the Dead, Healing Process, Ball Lightning, Telepathy/Thought Projection, Psychometry, Clairvoyance/Remote Viewing/ Out of the Body Experience, Precognition, and Retrocognition.

Lastly, there are two remaining items which the author wishes to touch upon:

A. The author has previously mentioned the Christian message, the three main points of which are:

1) that Heaven and Hell are real!

2) that the Body and the Soul are intimately related. For example, the doctrine of the Nicolaitans is that the Body and the Soul are totally disconnected so that they can sin all they want in the Body and their Soul will still go to Heaven. See how Jesus feels about this in Revelations 2:15.

3) a person cannot enter into Heaven unless they believe that Jesus Christ is the Son of God.

B. The author would like to point out that we, as a planet, are in the middle of one of the greatest type 1 miracles that is still in the process of unfolding:

Matthew 16:28

28 Verily I say unto you, there be some standing here, which shall not taste of death, till they see the Son of man coming in his kingdom.

The author interprets this to mean that somewhere on this earth there are one, two, or maybe three or more individuals from the time of Jesus who are still alive! How about that!

\section{References}

Bissonnet, P. (2015). A New Perspective on Advanced Space Travel. Journal of High Energy Physics, Gravitation and Cosmology, 1, 14-24. http://www.scirp.org/Journal/PaperInformation.aspx?PaperID=56925 https://doi.org/10.4236/jhepgc.2015.11002

Bissonnet, P. (2017a). The Search for New Physical Principles a Short Monograph on the 
Strange Consequences of Zero Inertia. (Unpublished) http://vixra.org/abs/1706.0480

Bissonnet, P. (2017b). A Short Monograph on a Curious Anomaly Regarding the so Called Gravitational “Constant”. (Unpublished) http://vixra.org/abs/1702.0149

Bissonnet, P. (2018). On the Concept of Representations of Prime Numbers and Prime Products. Journal of Mathematics Research, 10, 132-142. https://doi.org/10.5539/jmr.v10n1p132

Bord, J., \& Bord, C. (1989). Unexplained Mysteries of the 20th Century. Chicago, IL: Contemporary Books.

Carroll, R. T. (1994). Skeptic's Dictionary. skepdic.com. http://skepdic.com/auras.html

Collins, M. G. (2011). Walking on the Water (Part One). Church of the Great God. https://www.cgg.org/index.cfm/fuseaction/Library.sr/CT/BS/k/1520/Miracles-Jesus-Ch rist-Walking-on-Water-Part-One.htm

Keel, J. A. (1970). Operation Trojan Horse: The Classic Breakthrough Study of UFOs. San Antonio, Charlottesville: Anomalist Books.

Khan, A. (2009). The Changing Views of the Crucifixion. Review of Religions, reviewofreligions.org. http://www.reviewofreligions.org/1440/the-changing-views-of-the-crucifixion/

Krippner, S., \& Rubin, D. (1974) The Kirlian Aura-Photographing the Galaxies of Life. Garden City, New York: Anchor Books, Anchor Press/Doubleday.

Lillie, B. (2014). "Madonna with Saint Giovannino": UFO_Inspired Art? Italy Magazine. http://www.italymagazine.com/news/madonna-saint-giovannino-ufo-inspired-art

Lin, K. (2016). Madonna with Saint Giovannino: Painting with a UFO? Historic Mysteries. https://www.historicmysteries.com/madonna-with-saint-giovannino/

Watson, S. (2005). How Spontaneous Human Combustion Works. https://science.howstuffworks.com/science-vs-myth/unexplained-phenomena/shc.htm

Webber, B. (2005). Gauge Field Theory (Handout). University of Cambridge, Department of Physics, High Energy Physics, Cavendish Laboratory. http://www.hep.phy.cam.ac.uk/theory/webber/GFT/gft_handout2_06.pdf

Williams, B., \& Ventola, A. (2011). Poltergeist Phenomena: A Primer on Parapsychological Research and Perspective. PublicParapsychology.org. http://publicparapsychology.org/Public\%20Parapsych/Poltergeist\%20Phenomena\%20P rimer\%20Final.pdf 